\title{
DESIGN AND OPTIMIZATION APPROACH FOR THE MAGNETIC COMPONENTS OF A FIVE-LEVEL CURRENT SOURCE RECTIFIER
}

\author{
Lisandra K. Ries ${ }^{1}$, Marcelo L. Heldwein ${ }^{2}$ \\ ${ }^{1}$ Instituto Federal de Santa Catarina, Florianópolis - Santa Catarina, Brasil \\ ${ }^{2}$ Universidade Federal de Santa Catarina, Florianópolis - Santa Catarina, Brasil \\ e-mail: lisandra.ries@ifsc.edu.br, marcelo.heldwein@ufsc.br
}

\begin{abstract}
This work presents a design and optimization method of the five-level current source converter magnetics components, this is a contribution of this work, since the magnetics volume information of this topology lacks in the literature. The magnetics components are: the interphase transformers, the input and the output filter inductors. The converter volume is minimized when the magnetic components multi-domain optimization is done. The inductance values are defined with given constraints such as Electromagnetic Compatibility standards for differential mode filters, conduction and switching losses of the semiconductors and maximum current variation. This optimization is shown for two different converter switching frequencies: $45 \mathrm{kHz}$ and $150 \mathrm{kHz}$. The copper losses, iron losses and temperature rise are calculated and used for selecting the smallest volume of each magnetic component with given specifications. A 6-kW prototype with the optimized magnetics was constructed.
\end{abstract}

Keywords - Interphase transformer optimization, CLC filter optimization, de output filter optimization, magnetics multilevel converter optimization, currentsource converter.

\section{INTRODUCTION}

In this work the three-phase ac-dc current source rectifier (CSR) is assumed in an electric vehicle battery charger application [1]. In a 3-level CSR the output inductor is typically the bulkier component of the converter because it stores a largest amount of energy and inductors tend to have a relatively lower energy density $\left[\mathrm{J} / \mathrm{dm}^{3}\right]$ than capacitors. However, other passive devices are important to the CSR operation and must be properly specified and designed. Capacitors are used at the dc-port of the CSR to establish a low ripple dc voltage. They are manufactured by automated and standardized processes in industry and are commercially available in a fairly large range of specifications, from which temperature, voltage, current, capacitance and life cycle are the most relevant for power electronics applications. A CSR also requires an input filter placed at its ac-port, which limits the propagation of high frequency conducted electromagnetic emissions (CEEs) to the ac power source. Among the filter components of a typical CSR there are inductors and capacitors. Even though 3-level CSRs present desirable electrical characteristics, they are typically identified

Manuscript received 05/20/2021; first revision 09/21/2021; accepted for publication 10/06/2021, by recommendation of Editor Demercil de Souza Oliveira Jr. http://dx.doi.org/10.18618/REP.2021.4.0027 as not being the most compact converters. This comes from two main facts, namely: (i) they use two power semiconductors in series to form each switch, leading to increased conduction losses and cooling systems; and, (ii) the passive components are rather bulky. The first issue is being tackled by power semiconductor manufacturers that are researching on devices with low forward conduction voltage with bidirectional capabilities [2], [3]. The second issue can be improved with higher operating frequency and multilevel waveforms, as in a multilevel CSR.

A CSR with a higher number of levels can be used to reduce the passive components dimensions and 5-level CSRs are reported as an attractive solution [4]. It is possible to use two 3-level CSRs connected in parallel to build a 5level CSR having, thus the 3-level CSR as its building block as seen in [5]-[8]. Another option to reduce size is to use interphase transformers (IPTs) at the 3-level CSRs dc-ports to limit the circulating current among them in the 5-level structure [1], [5], [9]-[11]. This power structure is seen in Figure 1 and its operation is reported in [12]. The advantage of interphase transformers over two loosely coupled inductors or two independent inductors is that the IPTs cores ideally are only subjected to ac flux and the component does not store energy. Thus, they can be advantageously built with ferrite cores and operate at relatively high frequency. The output inductors filter the resulting voltage, which presents voltage levels with reduced amplitude and higher effective frequency due to the IPTs. The output inductors need to store energy and, thus, the main options for their core materials are cores with distributed gap such as iron powder and cores with air gap, such as ferrite, amorphous and nanocrystalline. In this context, the magnetic components of a IPTs-based 5-level CSR to be custom designed are the interphase transformers, the output inductor and the filter inductors. Since the specific design of components for the 5-level CSR lacks in the literature, a procedure for their specification and design is proposed in this work. The procedure accounts for the system level influence of the passive components on the electrical, energetic and thermal performances of the converter.

The designs of the interphase transformers, ac-port filter and output inductors can be formulated as multi-domain optimization problems similar to the one reported in [13] for voltage source converters. The magnetic components optimization is a fundamental step in reducing a power converter volume [14]-[16]. In the IPTs case it is related to the transverse or circulating currents minimization and to the semiconductors switching frequency and generated losses. The ac-port filter design case depends mainly on the filter parameters selection in order to comply to electromagnetic 


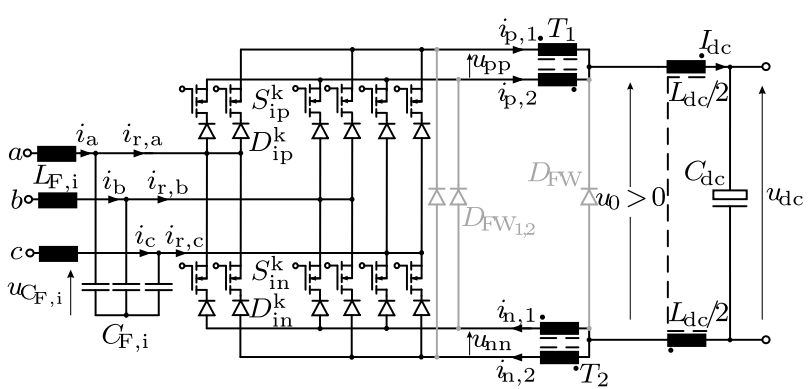

Fig. 1. Five-level CSR power circuit schematics including its main components, where $C_{\mathrm{dc}}$ is the dc-port capacitor, $T_{1}$ and $T_{2}$ are interphase transformers (coupled inductors), $L_{\mathrm{dc}}$ is the output inductor, $L_{\mathrm{F}}$ is the ac-port filter inductor, $C_{\mathrm{F}}$ is the ac filter capacitor. Optional positioning of freewheeling diodes are drawn in gray.

compatibility (EMC) standards. The output filter selection is related to the output current ripple amplitude and associated losses. Another important parameter is the definition of appropriate inductance values for the different magnetic components to satisfy the imposed operation constraints.

Two types of core are considered in the proposed optimization, namely E-shaped and toroidal cores. For the interphase transformer the optimization is exemplarily performed with E-shaped cores. This choice is justified by the possibility of using a core with lower magnetic induction. This is used to demonstrate the need to balance the IPTs currents since unbalance in the currents leads to the transverse mode flow to reach higher values. Current balance control is required so that these values do not reach the saturation. In addition, the magnetic flux in these components is ideally alternate at the switching frequency, i.e., no dc level is expected and the main frequency components are at relatively high frequencies. Thus, E-type ferrite cores are well suited. Toroidal cores made of iron powder material are used for ac- and dc-side filter inductors. In this case, the cores are subjected to relatively high dc or low frequency flux levels, while the superimposed high frequency ripple is relatively small. Thus, the higher flux saturation levels of iron powder materials typically lead to smaller inductors.

A steady state thermal model for the designed inductors is employed in order to estimate the temperature rise and these models were included in the optimization of the designed components. Material properties parameters are modified according to the computed operating temperature. The temperature influence on iron losses are small for the iron powder cores and are, thus, neglected.

The optimization uses current and induction curves obtained from the simulation for the converter operation worst cases at two different switching frequencies, namely: $45 \mathrm{kHz}$ and $150 \mathrm{kHz}$. The switching frequency choice is latter justified by the optimization results. For the definition of the optimal frequency for passive components volume minimization, the reader should apply the presented methodology scanning a design space where the switching frequency is the main parameter to vary within a set range. A design is exemplarily discussed throughout the paper to illustrate the proposed procedure and experimental results from a 6-kW 5-level CSR prototype that uses the designed components are presented to validation.

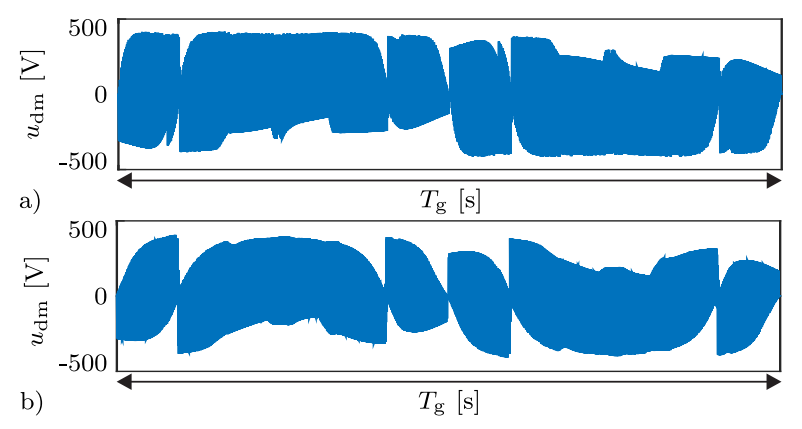

Fig. 2. Simulated differential mode voltage $u_{\mathrm{dm}}$ assuming the minimum input voltage condition without an input filter for the following switching frequency cases: (a) $45 \mathrm{kHz}$; and, (b) $150 \mathrm{kHz}$.

\section{INDUCTANCE VALUES DEFINITION}

The optimization of the magnetic components should be performed considering the worst case based on the design specifications. This section discusses how to specify the required inductance values for each of the magnetic components based on EMC requirements for the filter inductors, impact on semiconductor losses for the interphase transformers and ripple current for the output inductor.

\section{A. Modulation index}

Considering that the mains line-to-line voltage, $U_{\mathrm{g}, 1-\mathrm{l}}^{\mathrm{rms}}$, varies between two extreme values, exemplarily $U_{\mathrm{g}, 1-1, \min }^{\mathrm{rms}} . U_{\mathrm{g}, 1-1, \max }^{\mathrm{rms}}=342 \mathrm{~V} . .418 \mathrm{~V}$, the modulation index, $M$, varies accordingly between a minimum and a maximum value in the range $M_{\min } . . M_{\max }=0.742 . .0 .907$. This defines the operation range of the converter.

\section{B. Differential Mode Input Filter Inductance}

The design of the input filter is performed taking into account Electromagnetic Compatibility (EMC) standards for differential mode filters. CISPR Class B levels for quasi-peak $(\mathrm{QP})$ are used. The differential mode (DM) voltage is assumed symmetric and is calculated for phase $a$ as

$$
u_{\mathrm{dm}}=\frac{2}{3} u_{\mathrm{an}}-\frac{1}{3} u_{\mathrm{bn}}-\frac{1}{3} u_{\mathrm{cn}} \text {. }
$$

A simulation of the 5-level current source converter operating at full load without an input filter is performed. Circuit simulation is used because the time behavior of the involved electric quantities is highly complex. In addition, the defined EMC standards measurement procedure leads to nonlinear behaviors and, thus, time consuming even for computer simulations. The differential mode voltage is measured during one grid period $T_{\mathrm{g}}$ for the minimum input voltage condition and for the switching frequencies of $f_{\mathrm{sw}}=45 \mathrm{kHz}$ and $f_{\mathrm{sw}}=$ $150 \mathrm{kHz}$ (Figure 2).

The spectrum of the DM signal and the estimated quasipeak values for the frequency range of $9 \mathrm{kHz}$ to $1.5 \mathrm{MHz}$ is seen in Figure 3. The employed simulation software is GECKOCircuits [17] and the QP estimation is made within the software.

The attenuation required by the differential mode filter can be calculated with

$$
A t t_{\text {req,dm }}\left(f_{\text {int }}\right)=20 \cdot \log \left(\frac{U_{\mathrm{dm}}\left(f_{\text {int }}\right)}{1 \mu V}\right)-\text { Limit }_{\text {ClassB }}\left(f_{\text {int }}\right)+\text { Margin. }
$$

from the difference of the quasi-peak value and the limit value at the interest frequency $\left(f_{\text {int }}\right)$, which is the first multiple of 


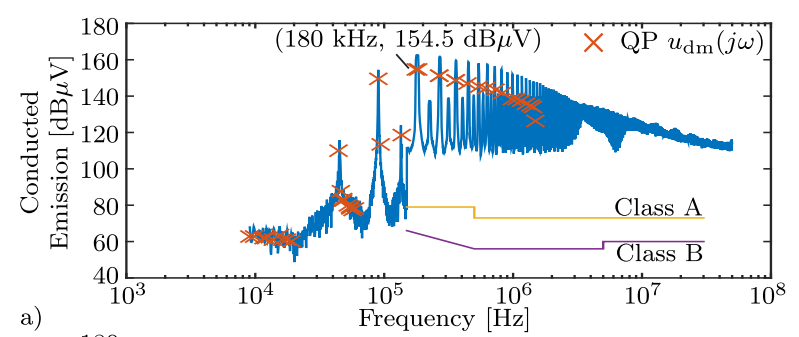

a)

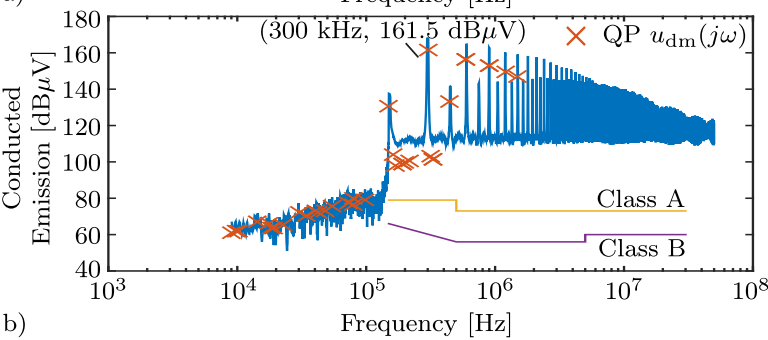

Fig. 3. Predicted harmonic spectra and quasi-peak detection value estimations (QP) for the DM voltage conducted emissions assuming the worst case without input filter for the switching frequencies: a) $45 \mathrm{kHz}$; and, b) $150 \mathrm{kHz}$.

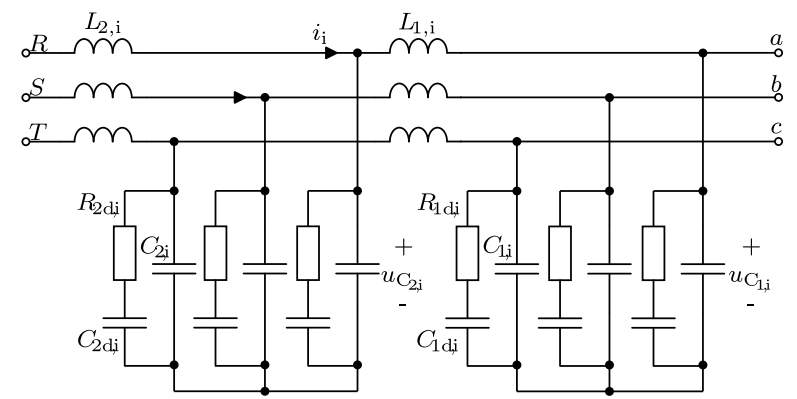

Fig. 4. Filter that can be used to fulfill the electromagnetic compatibility standard EN55022 employed in the 5L-CSR.

the switching frequency that is within the standard specified range. For the $45 \mathrm{kHz}$ and $150 \mathrm{kHz}$ switching frequencies the interest frequency are, $180 \mathrm{kHz}$ and $300 \mathrm{kHz}$, respectively. A margin of $6 \mathrm{~dB}$ is suggested [18].

The chosen input filter topology is a two-stage $L C$ filter with capacitor series damping as in Figure 4. Filter attenuation is chosen to be higher in the first stage of the filter, $A t t_{\mathrm{n} 1}\left(f_{\text {int }}\right)$, to simplify the dynamic behavior, resulting in a lower cut-off frequency. A $40 \mathrm{~dB}$ higher attenuation is suggested [18]. Thus,

$$
\begin{aligned}
& A t t_{\mathrm{n} 1}\left(f_{\text {int }}\right)=\left(\frac{A t t_{\text {req,dm }}\left(f_{\text {int }}\right)+40}{2}\right), \\
& A t t_{\text {n2 }}\left(f_{\text {int }}\right)=A t t_{\text {req, dm }}\left(f_{\text {int }}\right)-A t t_{\text {n1 }}\left(f_{\text {int }}\right),
\end{aligned}
$$

where $A t t_{\mathrm{n} 2}\left(f_{\mathrm{int}}\right)$ is the attenuation of the second filter stage.

The first stage cut-off frequency, $f_{\mathrm{c} 1}$, is typically set at a decade below the second stage cut-off frequency, $f_{\mathrm{c} 2}$, so that,

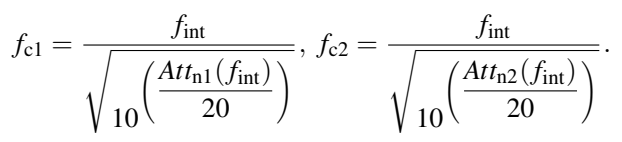

The following sequence of calculations [19] is performed for the choice of filter parameters and the combination that results in a lower volume is selected:

1. The variation of the peak-to-peak input voltage across the capacitor, $\Delta U_{\mathrm{CF}, \max }$, is limited between $1 \% \ldots 8 \%$. Thus, $C_{1}$ is calculated with

$$
C_{1}=I_{\mathrm{dc}} M_{\max } \frac{\left(1-M_{\max }\right)}{\Delta U_{\mathrm{CF}, \max } 2 f_{\mathrm{sw}}} .
$$

\section{TABLE I}

Two-stage input filter parameters selection for the $45 \mathrm{kHz}$ and $150 \mathrm{kHz}$ switching frequencies, using class X2 capacitors.

\begin{tabular}{cccccccc}
\hline$f_{\mathrm{sw}}[\mathrm{kHz}]$ & $C_{1}[\mu \mathrm{F}]$ & $L_{1}[\mu \mathrm{H}]$ & $C_{1 \mathrm{~d}}[\mu \mathrm{F}]$ & $r_{1 \mathrm{~d}}[\Omega]$ & $C_{2}[\mathrm{nF}]$ & $C_{2 \mathrm{~d}}[\mathrm{nF}]$ & $r_{2 \mathrm{~d}}[\Omega]$ \\
\hline 45 & 4.7 & $\mathbf{4 1 7 . 7}$ & 4.7 & 15 & 470 & 470 & 15 \\
150 & 4.7 & $\mathbf{2 8 6 . 6}$ & 4.7 & 12 & 270 & 270 & 22 \\
\hline
\end{tabular}

2. Inductance $L_{1}$ is

$$
L_{1}=\frac{1}{4 \pi^{2} f_{\mathrm{c} 1}^{2} C_{1}} .
$$

3. Capacitor $C_{1 \mathrm{~d}}$ is computed assuming a damping factor of $n=1$. Thus, $C_{1 \mathrm{~d}}=C_{1} \cdot n$.

4. The damping resistor $r_{1 \mathrm{~d}}$ is computed with the optimum damping factor assuming only the first filter stage that gives

$$
r_{1 \mathrm{~d}}=\sqrt{\frac{L_{1}}{C_{1}}} \sqrt{\frac{(2+n)(4+3 n)}{2 n^{2}(4+n)}} .
$$

5. The second filter stage is calculated considering an internal grid inductance of $50 \mu \mathrm{H}$. Its capacitance can be calculated with

$$
C_{2}=\frac{1}{4 \pi^{2} f_{\mathrm{c} 2}^{2} L_{\mathrm{g}}} .
$$

6. The other components of the filter, such as $C_{2 \mathrm{~d}}$ and $r_{2 \mathrm{~d}}$, are calculated using the same expressions used in the first stage.

7. The total volume of the filter is calculated with the volumetric coefficients of the film capacitors, $k_{\mathrm{C}}$, and inductors, $k_{\mathrm{L}}$,

$$
\mathrm{Vol}=k_{\mathrm{C}}\left(C_{1}+C_{2}+C_{2 \mathrm{~d}}\right) U_{\mathrm{Clrms}}^{2}+k_{\mathrm{L}} L_{1} I_{\mathrm{L} 1 \mathrm{rms}}^{2},
$$

which are assumed as in [19].

8. The power factor angle, $\delta$, should be limited. It is assumed lower than $\delta=5^{\circ}$ so that the expression $\delta \leq$ $\tan ^{-1}\left(\left(C_{1}+C_{1 \mathrm{~d}}+C_{2}+C_{2 \mathrm{~d}}\right) \omega_{\mathrm{g}} \frac{\hat{U}_{\mathrm{g}, \min }}{\hat{I}_{\mathrm{g}, \text { max }}}\right)$ holds.

The input filter self-inductance value $L_{1}$ is defined after applying the previous volume minimization sequence. For the switching frequencies of $45 \mathrm{kHz}$ and $150 \mathrm{kHz}$ the optimization results are summarized in Table I. Interestingly, the resulting first stage capacitance values for minimum volume filters are similar. However, inductances and second stage capacitances are reduced for the higher frequency specification.

Figure 5 shows the attenuation curves achieved using the calculated input filter. The Class B limits are fulfilled for the two switching frequencies.

The effect of the dc component should be taken into account in the input filter design, since the $60 \mathrm{~Hz}$ waveform is a considerable low frequency when compared to $f_{\text {sw }}$. The minimum value of the inductances need to be guaranteed at the peak value of the ac current at the worst condition.

The differential mode voltage is estimated again with the insertion of the input filter as shown in Figure 6. The resulting waveform is highly attenuated when compared to Figure 2. It presents predominantly low frequency components.

\section{Interphase Transformer}

The choice of the self inductance value of the interphase transformers (IPTs) is done here based on the influence it has on conduction and switching losses of the semiconductors. The current through each winding can be split into two 

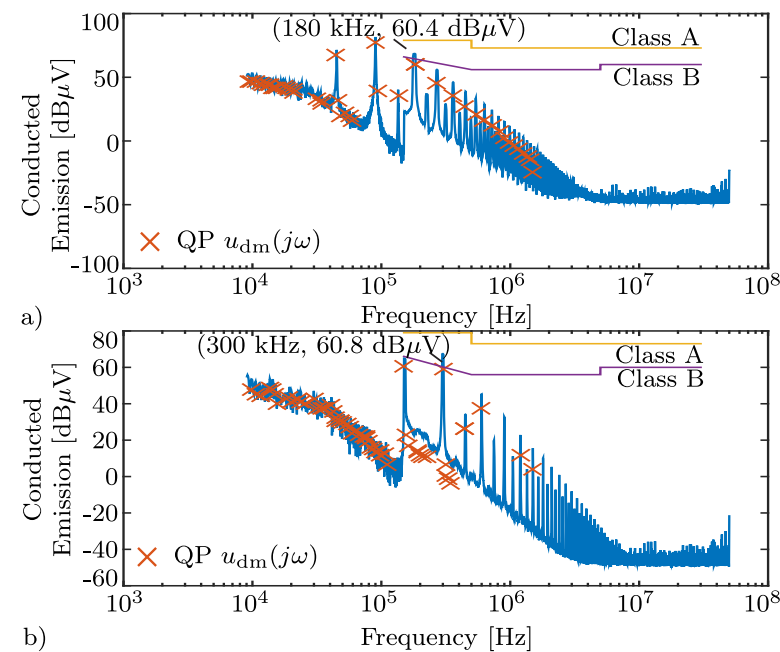

Fig. 5. Predicted harmonic spectra and the computed quasi-peak detection for the differential mode voltage conducted emissions for the worst case after using the input filter. The CISPR Class B standard is met for both switching frequency cases: a) $45 \mathrm{kHz}$; and, b) $150 \mathrm{kHz}$

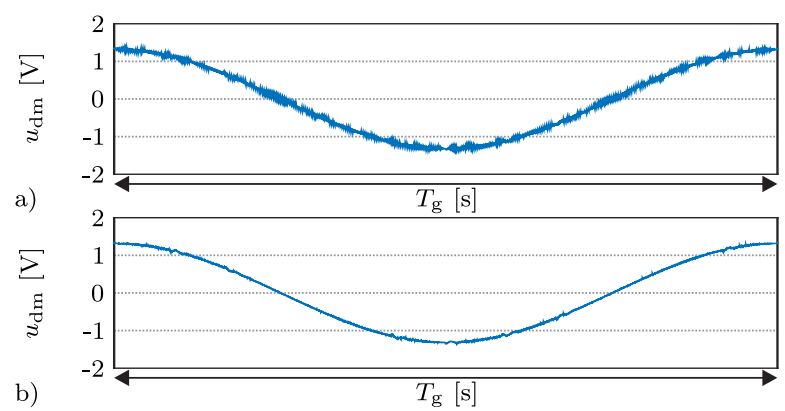

Fig. 6. Simulated differential mode voltage with minimum input voltage condition, with input filter and for the following switching frequency cases: (a) $45 \mathrm{kHz}$; (b) $150 \mathrm{kHz}$.

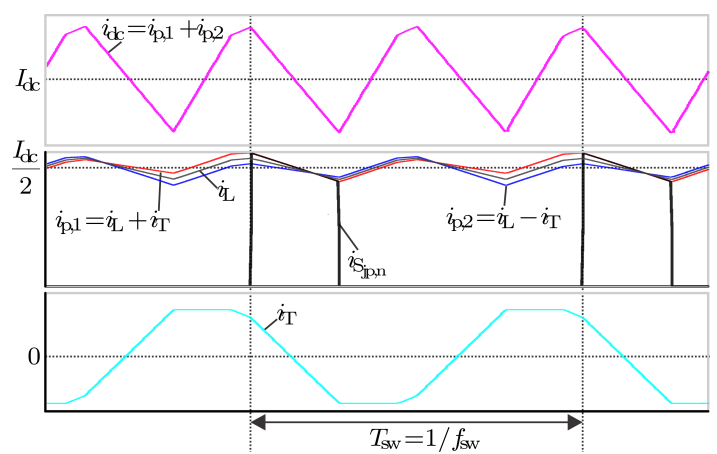

Fig. 7. Composition of the currents in a semiconductor from the longitudinal and transverse mode current components. Note that this a waveform simulation, bringing the details of the semiconductor within a switching period.
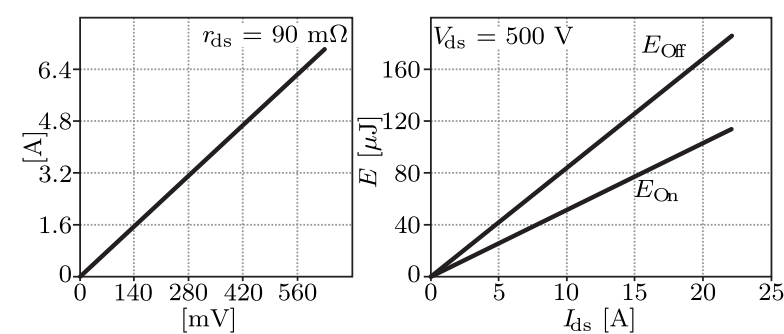

Fig. 8. On-state resistance and switching energies considering the SiC MOSFET C3M0075120K available from Cree.

TABLE II

Conduction and switching losses considering the input voltage variation 418 V..380 V..342 V and switching frequencies of $45 \mathrm{kHz}$ and $150 \mathrm{kHz}$.

\begin{tabular}{cccc|ccc}
\hline \multicolumn{3}{c|}{$45 \mathrm{kHz}$} & \multicolumn{3}{c}{$150 \mathrm{kHz}$} \\
\hline & $M_{\min }$ & $M$ & $M_{\max }$ & $M_{\min }$ & $M$ & $M_{\max }$ \\
\hline$P_{\text {cond }}[\mathrm{W}]$ & 55.2 & 58.5 & 62.4 & 55.2 & 58.5 & 62.4 \\
$P_{\text {com }}[\mathrm{W}]$ & 12.3 & 11.1 & 10.0 & 40.9 & 37.1 & 33.4 \\
$P_{\text {total }}[\mathrm{W}]$ & 67.5 & 69.6 & 72.4 & $\mathbf{9 6 . 1}$ & 95.6 & 95.8 \\
\hline
\end{tabular}

components, namely: (i) a longitudinal mode component, $i_{\mathrm{L}}$; and, (ii) a transverse mode one, $i_{\mathrm{T}}$, [20]. The transverse mode current rate of change is modified by varying the voltages applied to the IPTs windings, i.e., $u_{\mathrm{pp}}$ and $u_{\mathrm{nn}}$. This current component flows only through the semiconductor devices and, thus, impacts their conduction and switching losses. Figure 7 shows an example of the current composition in one of the semiconductors of the 5-level CSR, where the longitudinal and transverse mode currents of the interphase transformer form, for instance, the first winding current $\left(i_{\mathrm{p}, 1}\right)$, i.e., $i_{\mathrm{p}, 1}=$ $i_{\mathrm{L}}+i_{\mathrm{T}}$. The current in the semiconductor $i_{S_{\mathrm{i}, \mathrm{pn}}}$ equals the current $i_{\mathrm{p}, 1}$ at the time intervals when it conducts. The currents in the windings of one of the IPT, $i_{\mathrm{p}, 1}$ and $i_{\mathrm{p}, 2}$, present ripple frequency mainly at $2 f_{\mathrm{sw}}$, as do $i_{\mathrm{L}}$ and $i_{\mathrm{dc}}$. The ripple of the current $i_{\mathrm{dc}}$ is mainly limited by the output inductance and also affects the semiconductors losses value, because the ripple is proportional to the longitudinal mode current, which also circulates in the semiconductors. The ripple frequency of the currents through the switches and of the transverse mode current is $f_{\text {sw }}$.

The influence of the transverse mode current change rate on the conduction and switching losses is verified with simulations from GECKOCircuits software. A loss energy table showing the expected turn on and turn off values is created [21] with loss information from the device datasheet (Figure 8). The calculated results for both switching frequencies are summarized in Table II. It is verified that the switching losses influence are more relevant at $150 \mathrm{kHz}$ frequency.

The highest overall loss occurs with the minimum modulation index case. Thus, this is used in the further simulations, where the IPT inductance value is varied and the resulting losses in the semiconductors are evaluated. Figure 9 presents the results for both switching frequencies. The simulated results was close to the calculated value, which does not vary with the inductance value since its calculation does not consider, neither, the rate of change of the output current, nor the transverse mode currents. When the inductance is reduced the rate of variation of the transverse mode current 


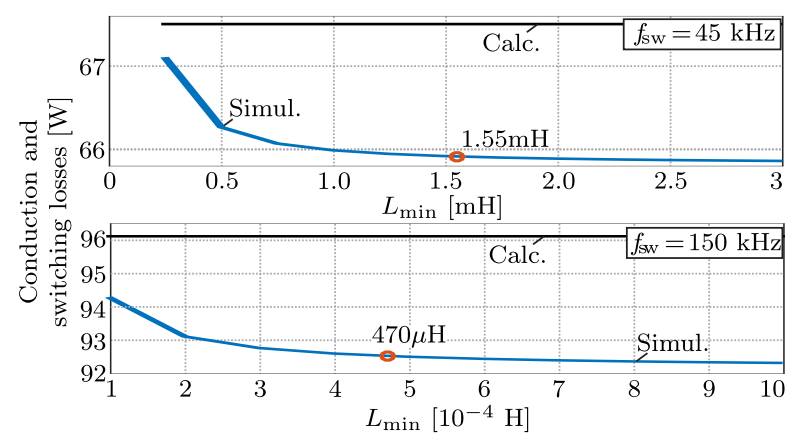

Fig. 9. Interphase transformer self-inductance value choice for the $45 \mathrm{kHz}$ and $150 \mathrm{kHz}$ switching frequencies, considering the losses in the semiconductors.

increases and, thus, the losses increase. The chosen values limit the transverse mode current variation rate by $0.8 \mathrm{~A}$. The inductances of $1.55 \mathrm{mH}$ and $470 \mu \mathrm{H}$ are chosen for the frequencies of $45 \mathrm{kHz}$ and $150 \mathrm{kHz}$, respectively, since further increasing their values has almost no effect on reducing losses.

\section{Output Filter Inductance}

A predominantly dc current is required for the converter to operate as expected. Thus, a limited ripple is required. The output current rate of change is maximum for the case of lower modulation index. The output filter is designed considering that the maximum current variation is $\Delta i_{\mathrm{L}_{\mathrm{dc}}}^{\mathrm{pp}} \leq 30 \%$ and using

$$
L_{\mathrm{dc}, \min }=\frac{U_{\mathrm{dc}}}{\Delta i_{\mathrm{L}_{\mathrm{dc}}}^{\mathrm{pp}} 2 f_{\mathrm{sw}}}\left(1-M_{\mathrm{min}}\right) .
$$

In practice this inductance also limits the total current ripple in the semiconductors since the output current is proportional to the longitudinal mode current, which also circulates through the semiconductors (see Figure 7). This effect has less influence on the semiconductors losses because the distribution of the longitudinal portion is balanced among all the semiconductors, differently from the transverse portion.

The specified inductance values for the output filter are: $L_{\mathrm{dc}}$ $=230 \mu \mathrm{H}$ and $L_{\mathrm{dc}}=70 \mu \mathrm{H}$ for $45 \mathrm{kHz}$ and $150 \mathrm{kHz}$ switching frequencies, respectively. The effect of the dc component is taken into account in the output filter design.

\section{GEOMETRIC PARAMETERS}

Cores with EE and toroidal geometries are used in the magnetic components design. Their parameters are defined in Figure 10. Other relevant data from the manufacturers datasheets are the core cross-sectional area $A_{\mathrm{e}}$, the effective magnetic mean path length $l_{\mathrm{e}}$ and the core volume $V_{\mathrm{e}}$.

Copper wires are used for the construction of the windings. If the winding has more than one wire, the Litz wire structure is considered. A four-wire winding in parallel is shown in Figure 11. In this case the wire thickness $d_{\mathrm{i}}$ will be modified by the factor $\sqrt{k}=2$. The copper wire thickness neglecting its insulation is represented by $d_{\mathrm{b}}$.

The mean length turn, $l_{\mathrm{t}}$, is calculated with the mean between the maximum and minimum values that one turn can occupy in the EE core and in the toroidal core. Thus,

$$
\begin{array}{ll}
l_{\mathrm{t}}=2 D 1+D 3+2 l_{\mathrm{C}}+D 2-2 D 4, & (\mathrm{EE}) \\
l_{\mathrm{t}}=2 D 3+D 1-D 2 / 2, & (\text { Toroid })
\end{array}
$$
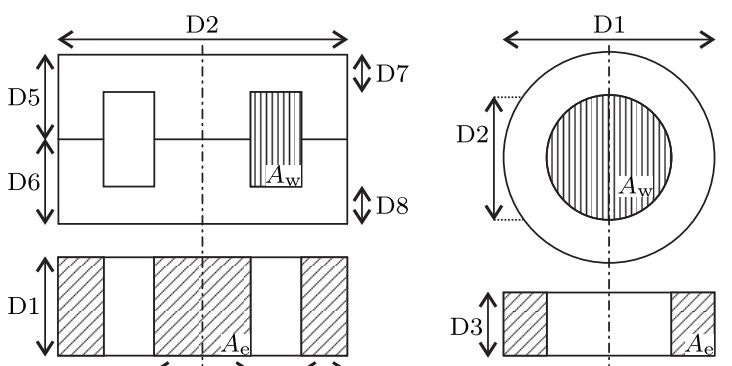

a)

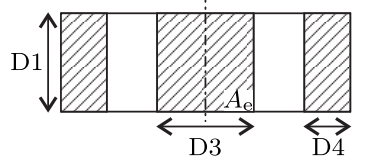

b)

Fig. 10. Main dimensions for the considered core geometries: a) EE; and, b) Toroid.

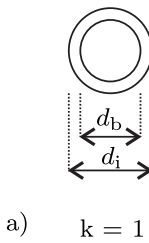

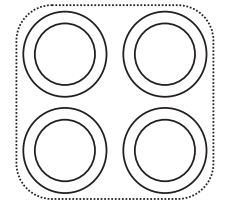

$\mathrm{k}=4$

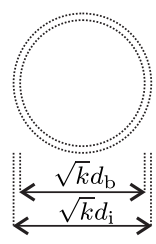

Fig. 11. Considered winding structures based on round copper wires and their representation when considering $k$ wires in parallel: a) single wire; and, b) four parallel wires and equivalent structure.

where the coil former or insulation thickness is $l_{\mathrm{C}}$.

The winding factor $K_{\mathrm{w}}$ represents the fraction of the core window area $A_{\mathrm{w}}$ that is filled by $N$ copper wires. It is calculated according to

$$
\begin{aligned}
K_{\mathrm{w}} & =\frac{N \pi d_{\mathrm{i}}^{2} k}{2\left(D 2-D 3-2 D 4-2 l_{\mathrm{c}}\right)\left(D 5+D 6-2 D 7-2 l_{\mathrm{c}}\right)},(\mathrm{EE}) \\
K_{\mathrm{w}} & =\frac{N d_{\mathrm{i}}^{2} k}{D 2^{2}}, \text { (Toroid) }
\end{aligned}
$$

and the maximum winding factors are $60 \%$ for the EE geometry and $40 \%$ for the toroids.

The maximum number of conductors per layer within the window area of the EE core can be found with

$$
n_{\mathrm{max}, \mathrm{l}}=\text { floor }\left(\frac{D 5+D 6-2 D 7-2 l_{\mathrm{C}}}{d_{\mathrm{i}} \sqrt{k}}\right) .
$$

and the estimated number of layers is given by

$$
n_{\mathrm{l}}=\frac{N}{n_{\max , 1}} .
$$

Figure 12(a) represents the arrangement of conductors within the window area for an EE core. The maximum number of conductors per layer is an integer number, so the floor function is used, which rounds down the specified expression.

For the toroidal geometry the maximum number of conductors per layer can be estimated with

$$
n_{\max , \mathrm{l}}=\text { floor }\left[\pi\left(\frac{D 2}{d_{\mathrm{i}} \sqrt{k}}-(2 l-1)\right)\right], l \geq 1,
$$

where the corresponding layer is given by $l$.

The process of calculating the number of layers is iterative. The procedure considers that the first layers are fully occupied. Then the amount of conductors arranged in the last layer is estimated and the proportion of conductors that last layer is finally computed. Figure 12(b) represents the arrangement of conductors within the window area for a toroid. In the first layer $n_{\max , 1}=14$ and in the second and last layer $n_{\max , 2}=8$. Only six conductors are part of the last layer, the number of layers for this condition is $n_{1}=1+6 / 8=1.75$. 


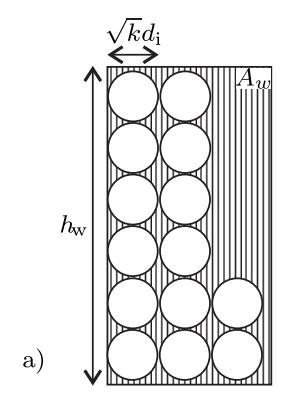

b)

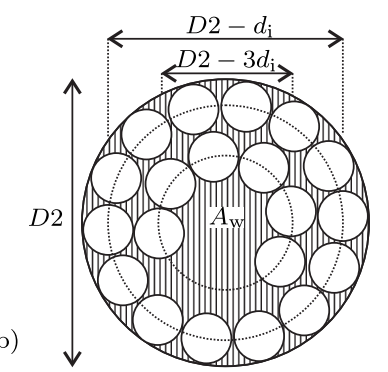

Fig. 12. Representation of the layers number calculation considering the geometries: a) EE; and, b) toroidal.
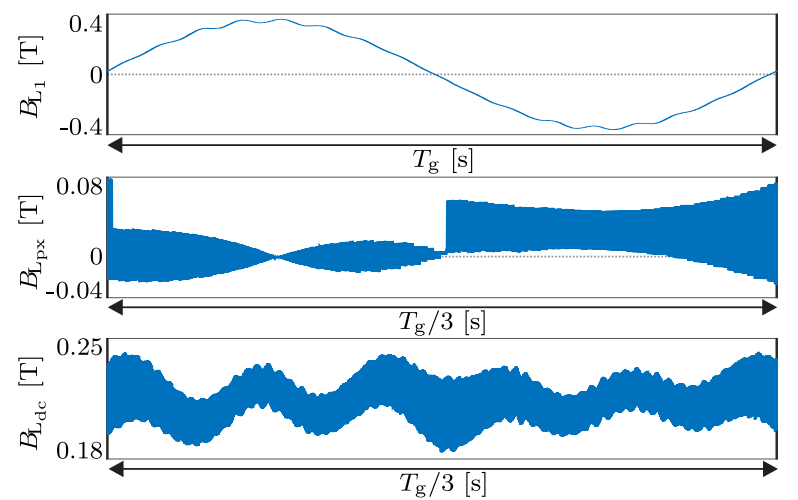

Fig. 13. Induction waveforms for magnetic components of the converter, where $B_{\mathrm{L}_{1}}$ is for the input filter inductor, $B_{\mathrm{L}_{\mathrm{px}}}$ is for the magnetization of one of the interphase transformers and $B_{\mathrm{Ldc}_{\mathrm{dc}}}$ is for the output inductor. The time axis presents one third of the mains period, which is enough to represent the repetition of the waveforms.

\section{MAGNETIC PARAMETERS}

The magnetic parameters of the considered cores define saturation and core loss behaviors. For example, the main magnetic parameters for the core E55/28/25 built with material N87 from Epcos working with magnetic field $H=250 \mathrm{~A} / \mathrm{m}$, frequency $f=10 \mathrm{kHz}$ and temperature $T=100^{\circ} \mathrm{C}$ are: inductance factor $A_{\mathrm{L}}=7300 \mathrm{nH}(+30 /-20 \%)$, effective relative permeability $\mu_{\mathrm{e}}=1740(+30 /-20 \%)$ and saturation induction $B_{\mathrm{S}}=310 \mathrm{mT}$. This data is temperature dependent. and is exemplarily used to define the chosen operation point.

The minimum self-inductance value $L_{\mathrm{p}, \min }$ is specified for a given operating point and the number of turns required for this realization is calculated with

$$
N=\sqrt{\frac{L_{\mathrm{p}, \min }}{A_{\mathrm{L}, \text { min }}}},
$$

where $A_{\mathrm{L}, \min }$ is within the given tolerance range.

The voltage waveform applied to the transformer primary and the inductor windings are drawn from the converter simulation for the worst case scenario. The induction waveform is derived from this voltage with

$$
B(t)=\frac{1}{A_{\mathrm{e}} N} \int_{0}^{T} v(t) d t .
$$

Thus, the induction waveform can be obtained with the geometric and magnetic core parameters. The different induction waveforms are shown in Figure 13. The induction is specified not to exceed $90 \%$ of the saturation limit for the core being evaluated within a possible optimal result.

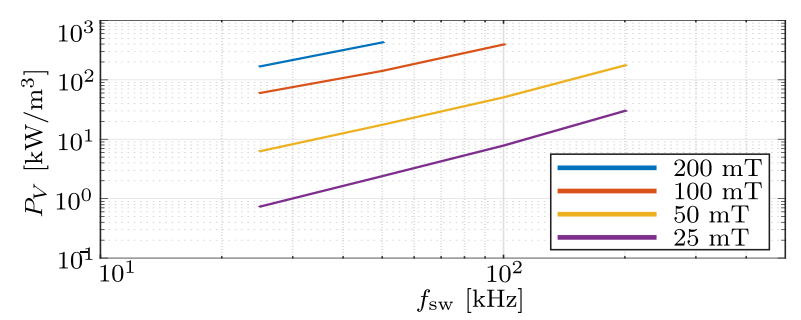

Fig. 14. Volumetric losses plot as a function of the frequency for different magnetic induction peak values and temperature of $100^{\circ} \mathrm{C}$ for the N87 material.

\section{A. Steinmetz Coefficients}

The Steinmetz coefficients are used for core losses calculation and must be obtained for each operation point. For each given operating frequency, peak induction and temperature, the obtained Steinmetz coefficients result in the volumetric losses extracted from the core material loss graphs. Figure 14 presents the volumetric loss plot for the temperature of $100^{\circ} \mathrm{C}$ for the $\mathrm{N} 87$ material. The Steinmetz equation at frequency $f_{\mathrm{sw}}$, peak induction $\hat{B}$ for the temperature of $100^{\circ} \mathrm{C}$ is defined with

$$
P_{\mathrm{V}}=k_{\mathrm{s}} f_{\mathrm{sw}}^{\alpha} \hat{B}^{\beta},
$$

where quadratic minimization methodology can be used to obtain the Steinmetz coefficients [22]. A $\rho$ matrix of order $i \times 3$ is synthesized from the volumetric losses data as in Figure 14. Thus,

$$
\rho=\left[\begin{array}{ccc}
f_{\mathrm{sw} 1} & \hat{B}_{1} & P_{1} \\
\vdots & \vdots & \vdots \\
f_{\mathrm{swi}} & \hat{B}_{\mathrm{i}} & P_{\mathrm{i}}
\end{array}\right]
$$

Matrices $\mathbf{A}_{\rho}, \mathbf{W}$ and $\mathbf{b}_{\rho}$ are used in the minimization, where $A_{\rho}$ has order $i \times 3, \mathbf{W}$ is a $i \times i$ diagonal matrix and vector $\mathbf{b}_{\rho}$ has order $i \times 1$. Their elements are defined with

$$
\begin{aligned}
A_{\rho_{\mathrm{i}, 1}} & =1, A_{\rho_{\mathrm{i}, 2}}=\log \left(\rho_{\mathrm{i}, 1}\right), A_{\rho_{\mathrm{i}, 3}}=\log \left(\rho_{\mathrm{i}, 2}\right), \\
W_{\mathrm{i}, \mathrm{i}} & =\frac{\varepsilon_{1}}{\left(\left|f_{\mathrm{sw}}-\rho_{\mathrm{i}, 1}\right|+\varepsilon_{2}\right)\left(\left|\hat{B}-\rho_{\mathrm{i}, 2}\right|+\varepsilon_{3}\right)},
\end{aligned}
$$

where $\varepsilon_{1}=10, \varepsilon_{2}=10^{-2}$ and $\varepsilon_{3}=10^{-2}$, and

$$
\mathbf{b}_{\rho_{\mathrm{i}, 1}}=\log \left(\rho_{\mathrm{i}, 3}\right) \text {. }
$$

The result vector $\lambda$, of order $i \times 1$, gives the desired coefficients and is given by

$$
\lambda=\left[\mathbf{A}_{\rho}{ }^{T} \mathbf{W} \mathbf{A}_{\rho}\right]^{-1} \mathbf{A}_{\rho}{ }^{T} \mathbf{W} \mathbf{b}_{\rho}=\left[\log \left(k_{\mathrm{s}}\right) \alpha \beta\right]^{T} .
$$

With the Steinmetz coefficients for various operation points, the volumetric losses curve can be drawn as a function of the magnetic induction and frequency for the temperature of $100^{\circ} \mathrm{C}$ as in Figure 15 . This procedure can be repeated for other temperatures to account for temperature dependent characteristics.

\section{COPPER LOSSES}

The copper losses can be modeled through equivalent resistances of the windings. The dc resistance is defined by the conductors geometry, resistivity, length and temperature. The resistance per unit length is found with

$$
\frac{R_{\mathrm{dc}}}{l_{\mathrm{b}}}=\frac{1}{\sigma\left(T_{\mathrm{f}}\right) A_{\mathrm{b}}},
$$

where $R_{\mathrm{dc}}$ is the dc resistance [ $\left.\Omega\right], l_{\mathrm{b}}$ is the winding length [m], $\sigma$ is the material conductivity, $T_{\mathrm{f}}$ is the operating temperature 


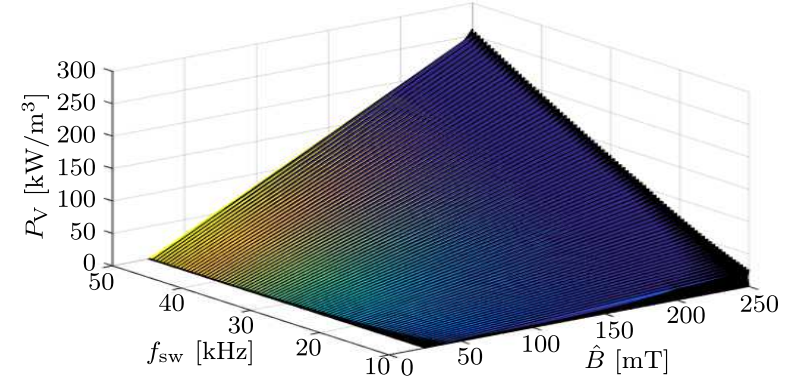

Fig. 15. Volumetric losses plot as a function of the magnetic induction and frequency for the temperature of $100^{\circ} \mathrm{C}$ using the described quadratic minimization procedure for the $\mathrm{N} 87$ Epcos material.
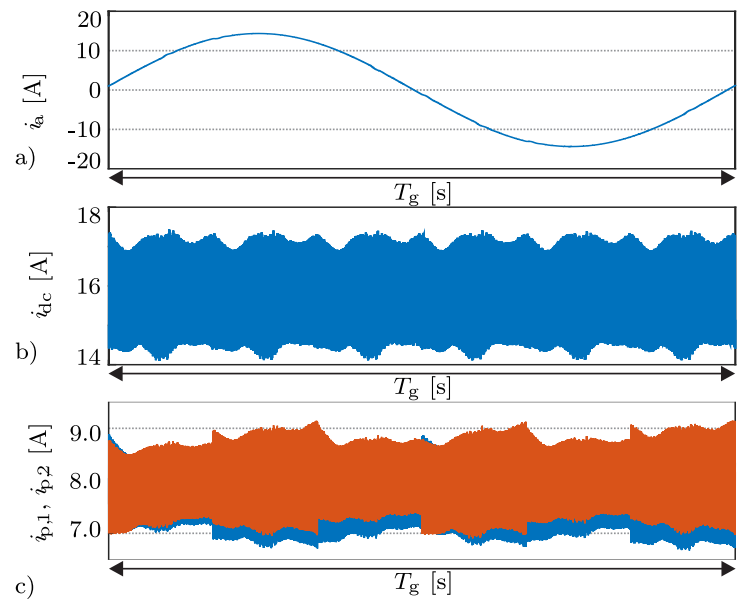

Fig. 16. Steady state waveforms of the currents: (a) at phase $a$ of the input filter $i_{\mathrm{a}}$; (b) at the output filter inductor $I_{\mathrm{dc}}$; and, (c) in the interphase transformer windings $i_{\mathrm{p}, 1}$ and $i_{\mathrm{p}, 2}$.

and $A_{\mathrm{b}}$ is the copper area. However, the operation of the magnetic components occurs in a large frequency range and skin and proximity effects must be included in the resistance model.

For the cases where the core does not present a relevant air gap Dowell's equation for round wires can be used [23]. This gives an estimation of the ac resistance $R_{\mathrm{ac}, \mathrm{n}}$ considering, both, skin and proximity effects. The expressions for the ac resistance are

$$
\begin{aligned}
R_{\mathrm{ac}, \mathrm{n}} & =R_{\mathrm{dc}} F_{\mathrm{r}, \mathrm{n}}, A_{\mathrm{n}}=\frac{\pi^{3 / 4}}{4} \frac{d_{\mathrm{b}} \sqrt{\eta_{\mathrm{b}}}}{\delta_{\mathrm{n}}}, \\
F_{\mathrm{r}, \mathrm{n}} & =A_{\mathrm{n}}\left[\frac{\sinh \left(2 A_{\mathrm{n}}\right)+\sin \left(2 A_{\mathrm{n}}\right)}{\cosh \left(2 A_{\mathrm{n}}\right)-\cos \left(2 A_{\mathrm{n}}\right)}+\frac{2}{3}\left(n_{1}^{2} k-1\right) \frac{\sinh \left(A_{\mathrm{n}}\right)-\sin \left(A_{\mathrm{n}}\right)}{\cosh \left(A_{\mathrm{n}}\right)+\cos \left(A_{\mathrm{n}}\right)}\right] .
\end{aligned}
$$

where $n$ is the current harmonic index, $F_{\mathrm{r}, \mathrm{n}}$ is the ac resistance factor for the $n^{\text {th }}$ harmonic, $\delta_{\mathrm{n}}$ is the copper penetration depth at the operating temperature for the $n^{\text {th }}$ harmonic, $\eta_{\mathrm{b}}$ is the porosity factor and $k$ is the number of conductors in parallel.

Dowell's equations are an appropriate equation to be used in optimization routines. The result can be latter refined through Finite Element simulations. If an air gaped core is used, other considerations must be made. It is not the case of this work because the EE core used in the interphase transformer does not have air gap. For the input and output filters, toroidal cores made with iron powder are used.
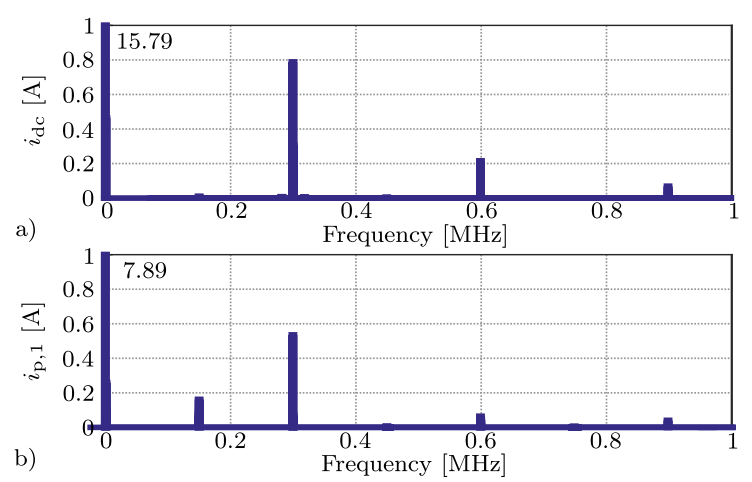

Fig. 17. FFT of currents: a) $I_{\mathrm{dc}}$ (output filter) and b) $i_{\mathrm{p}, 1}$ (interphase transformer).

\section{A. Current Spectra}

The characteristic waveforms for each magnetic component is seen in Figure 16. In the input filter the current $i_{\mathrm{a}}$ is mainly sinusoidal at the frequency of $60 \mathrm{~Hz}$. Interphase transformers are considered to be balanced, i.e., $i_{\mathrm{p}, 1}=i_{\mathrm{p}, 2}$ and $i_{\mathrm{n}, 1}=i_{\mathrm{n}, 2}$. The difference between the currents $i_{\mathrm{p}, 1}$ and $i_{\mathrm{p}, 2}$ shown in Figure 16 can be undestood by knowing that a simulation step is never small enough to eliminate such difference and that it depends on the simulation initial conditions.

The current harmonic spectra are seen in Figure 17. For the input filter only the $60 \mathrm{~Hz}$ component is considered, since the upper frequencies do not present significant amplitude, contributing very little to the losses calculation. For the interphase transformer and output filter, the GECKOCircuits simulation tool is used to define frequency spectra up to $4 \mathrm{MHz}$. The transformer harmonic spectra is assumed similar for each winding. The largest current amplitude is dc, followed by multiple components of the switching frequencies. The output inductor has a dominant dc component. On the dc filter side the current has components that are multiples of $2 f_{\mathrm{sw}}$.

\section{B. Copper Losses Calculation in the Optimization Routine}

The copper loss is calculated if the presence of all current harmonic components with

$$
P_{\mathrm{W}}=R_{\mathrm{dc}} \sum_{n=1}^{\infty} F_{\mathrm{r}, \mathrm{n}} I_{\mathrm{n}, \mathrm{rms}}^{2} .
$$

Due to the high switching frequency, the cost of calculating the previous equation is very high in an optimization routine. It is considered that the current harmonic spectra is limited to $4 \mathrm{MHz}$. For the copper losses calculation, only the contribution of harmonic groups centered on multiple harmonics of the switching frequency is considered. Thus,

$$
P_{\mathrm{W}}=R_{\mathrm{dc}} \sum_{j=1}^{j_{\max }}\left[\sum_{n=n_{\mathrm{j}}-100}^{n_{\mathrm{j}}+100} F_{\mathrm{r}, \mathrm{n}} I_{\mathrm{n}, \mathrm{rms}}^{2}\right], n_{\mathrm{j}}=j \frac{f_{\mathrm{sw}}}{f_{\mathrm{g}}} .
$$

\section{CORE LOSSES}

The Steinmetz equation (equation (18)) is used to calculate the volumetric losses $P_{\mathrm{V}}$ given a sinusoidal excitation of peak induction $\hat{B}$ and frequency $f_{\mathrm{sw}}$. The major limitation of this equation is that it is only correctly applied to sinusoidal excitations. Figure 13 presents the different induction waveforms of the magnetic components. It is concluded that 
only the input filter has a sinusoidal induction waveform. The induction peak-to-peak variation $\Delta B$ of the interphase transformer and of the output filter is different for each interval in between on switching period $T_{\mathrm{sw}}$. The iGSE method (Improved Generalized Steinmetz Equation) improves the Steinmetz equation by considering that the losses from the domain walls movement are also related to the rate of change of induction $d B / d t$ and that smaller hysteresis loops are considered [24]-[26]. It can be applied to non sinusoidal waveforms. Thus, the volumetric loss is calculated here with the iGSE method and is given by

$$
P_{\mathrm{V}}=\frac{1}{T} \int_{0}^{T} k_{\mathrm{i}}\left|\frac{d B}{d t}\right|^{\alpha}(\Delta B)^{\beta-\alpha} d t
$$

where

$$
k_{\mathrm{i}}=\frac{k}{(2 \pi)^{\alpha-1} \int_{0}^{2 \pi}|\cos (\theta)|^{\alpha} 2^{\beta-\alpha} d \theta} .
$$

Parameters $k, \alpha$ and $\beta$ are the same used in the original Steinmetz formulation (equation (18)). Considering that the waveforms in Figure 13 are piecewise linear the energy per volume $E_{1}$ dissipated at each switching period within the period $T_{\mathrm{g}} / 3$ is

$$
E_{1}=\frac{k_{\mathrm{i}, 1}\left(\Delta B_{\mathrm{l}}\right)^{\beta_{1}-\alpha_{1}}}{\left(A_{\mathrm{e}} N\right)^{\alpha_{1}}} \sum_{n=1}^{6} v^{\alpha_{1}}\left(\Delta t_{\mathrm{n}}\right) \Delta t_{\mathrm{n}},
$$

where the index $l$ indicates the $l^{\text {th }}$ switching period, the index $n$ indicates the $n^{\text {th }}$ interval of one switching period and $v$ is the voltage waveform applied to the transformer primary or the inductor windings. In the case of the output inductor, the switching frequency must be updated to $2 f_{\text {sw }}$.

From the resulting expression, it is concluded that the Steinmetz coefficients are to be updated for each switching period since the peak induction varies. Voltage $v$ is also modified for each interval $\Delta t_{n}$ within a switching period. The average volumetric power dissipated by the core is calculated by

$$
P_{\mathrm{V}}=\frac{3}{T_{\mathrm{g}}} \sum_{l=1}^{T_{\mathrm{g}} /\left(3 T_{\mathrm{sw}}\right)} E_{\mathrm{l}} .
$$

Finally, the power dissipated in the core, $P_{\mathrm{C}}$, is given by

$$
P_{\mathrm{C}}=V_{\mathrm{e}} P_{\mathrm{V}} .
$$

\section{TEMPERATURE RISE}

A simple equation is widely used as a reasonably accurate method to predict the temperate rise [27] in magnetic components with natural convection. With this, the temperature rise $\Delta T_{\mathrm{E}}$ is estimated with

$$
\Delta T_{\mathrm{E}}=450\left[\frac{\left(P_{\mathrm{W}}+P_{\mathrm{C}}\right)}{10^{4} A_{\mathrm{t}}}\right]^{0.826},
$$

where $P_{\mathrm{C}}[\mathrm{W}]$ is the power loss of the core, $P_{\mathrm{W}}[\mathrm{W}]$ is the power loss of the winding and $A_{\mathrm{t}}\left[\mathrm{m}^{2}\right]$ is the effective surface area available to exchange heat with the environment. To correctly use this equation the transformer is ideally homogeneous, meaning that the thermal energy is dissipated uniformly through the surface area of the core and winding. The major flaw of this equation is that in an optimization result there may exist a large variation between the distribution of the core and winding losses.

To overcome this limitation, models for the temperature rise calculation must be created, both for $\mathrm{EE}$ ferrite core and for toroidal cores [28], [29]. Traditional studies of the toroidal thermal circuits consider uniform windings around the core, but an uneven winding distribution must be considered for a correct prediction of the temperature rise, since the conductor spacing is thicker on the inside and thinner on the outside [29]. There are two different thermal models, since there are two different main structures. It is possible to obtain the steady state temperature rise, by knowing the geometric parameters, the initial temperature $T_{\mathrm{i}}$, the operating temperature $T_{\mathrm{f}}$, the thermal characteristics information and core and winding losses.

\section{OPTIMIZATION METHODOLOGY}

The optimization flowchart is presented in Figure 18. The first step of optimization is to define the magnetic inductance value and design specifications. From the geometric information one can verify if a given structure is feasible. The magnetic parameters, such as saturation induction values, the relative permeability and the Steinmetz parameters are updated. The Steinmetz parameters are frequency, induction and temperature dependent, i.e., they are modified at each operating point. The objective of the optimization is to choose the lowest possible volume respecting the maximum temperature of $T_{\mathrm{f}, \max }=100^{\circ} \mathrm{C}$. The temperature rise $\Delta T_{\mathrm{C}}$ is calculated as a function of copper and iron losses using the thermal modeling of the magnetic components. These losses are temperature dependent, so some interactions must be made until the specified convergence of $0.01 \%$ is reached.

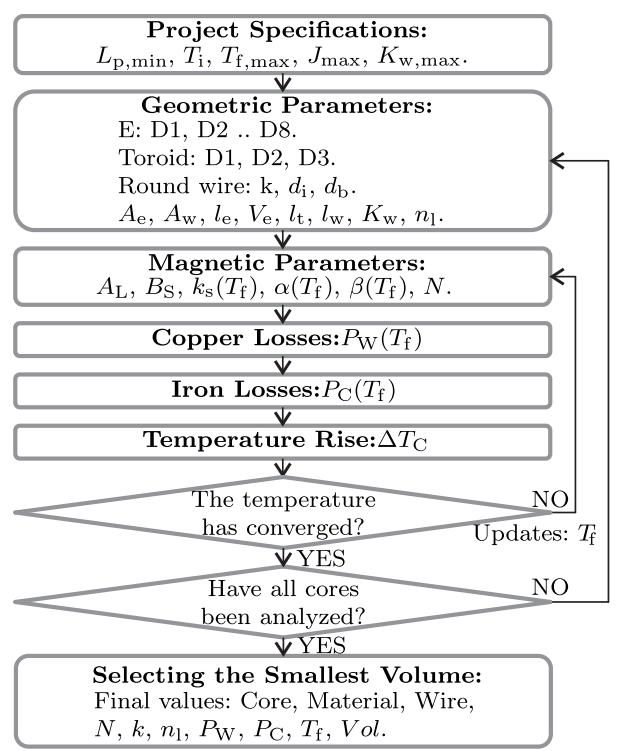

Fig. 18. Magnetic components optimization flow chart.

\section{OPTIMIZATION RESULTS}

The objective of this section is to present the optimization results using the presented methodology. The following magnetic components are optimized:

1. Input filter inductor: The induction waveform of this component has the characteristic of a sinusoid with a $60 \mathrm{~Hz}$ frequency. The employed core is a toroidal iron powder core of High Flux material (HF) available from Magnetics due to its high saturation value; 
2. Interphase Transformer: Ferrite $\mathrm{E}$ core is used with the materials N27, N41, N49, N72, N87, N92 and N97 (avialable from TDK). Its induction characteristic waveform has fundamental frequency of $3 f_{\mathrm{g}}$ and other harmonic components at multiples of this frequency and $f_{\text {sw. }}$.

3. Output inductor: Its current presents harmonic components at dc and multiples of $2 f_{\mathrm{sw}}$. Magnetics toroidal iron powder core is also used. The considered materials are High Flux (HF, $\left.B_{S}=1.5 \mathrm{~T}\right)$, Kool Mu (KM, $B_{\mathrm{S}}=1.0 \mathrm{~T}$ ) and Molypermalloy Powder (MPP, $B_{\mathrm{S}}=$ $0.75 \mathrm{~T})$.

Ambient temperature is assumed at $40^{\circ} \mathrm{C}$ and the worst cases are considered in the optimization. Table III presents the optimization results for the switching frequencies of $45 \mathrm{kHz}$ and $150 \mathrm{kHz}$. Results for each material are presented and the result presenting the lower volume is highlighted (bold). The minimum inductance value $L_{\mathrm{p}, \mathrm{min}}$, number of turns $N$, iron losses $P_{\mathrm{C}}$, copper losses $P_{\mathrm{W}}$ and final temperature $T_{\mathrm{f}}$ are shown in the table. It is verified that, for $150 \mathrm{kHz}$, the magnetic components have smaller volume as expected.

\section{TABLE III}

Optimization results for the worst operating case and $T_{\mathrm{a}}=40^{\circ} \mathrm{C}$ considering the following components: (a) Input filter inductor; (b) Interphase transformer; and, (c) Output inductor.

\begin{tabular}{lcccccccc}
\hline $\begin{array}{l}L_{\mathrm{p}, \min } \\
{[\mu \mathrm{H}]}\end{array}$ & Core & AWG & $N$ & $\begin{array}{c}P_{\mathrm{C}} \\
{[\mathrm{W}]}\end{array}$ & $\begin{array}{c}P_{\mathrm{W}} \\
{[\mathrm{W}]}\end{array}$ & $\begin{array}{c}T_{\mathrm{f}} \\
{\left[{ }^{\circ} \mathrm{C}\right]}\end{array}$ & $\begin{array}{c}\text { Vol } \\
{\left[\mathrm{dm}^{3}\right]}\end{array}$ & $\begin{array}{c}f_{\mathrm{sw}} \\
{[\mathrm{kHz}]}\end{array}$ \\
\hline (a) 417.7 & C058110 HF60 & 17 & 103 & $7.34 \mathrm{e}-3$ & 6.10 & 101.6 & $\mathbf{4 . 7 0 e - 2}$ & 45 \\
\hline (b) 1550 & E55/28/21 N87 & 12 & $2 \times 18$ & 0.98 & 3.37 & 93.4 & $\mathbf{5 . 7 3 e - 2}$ & 45 \\
\hline \multirow{2}{*}{ (c) 230} & 0058617 HF60 & 10 & 40 & 2.07 & 8.81 & 93.1 & $7.50 \mathrm{e}-2$ & 45 \\
& 77102A7 KM26 & 12 & 94 & 0.60 & 17.81 & 94.2 & $1.39 \mathrm{e}-1$ & 45 \\
& C055866 MPP125 & 10 & 64 & 1.23 & 11.8 & 93.5 & $\mathbf{6 . 5 5 e - 2}$ & 45 \\
\hline (a) 286.6 & C058089 HF125 & 13 & 67 & $2.35 \mathrm{e}-3$ & 4.32 & 92.2 & $\mathbf{2 . 8 8 e - 2}$ & 150 \\
\hline (b) 470 & E42/21/20 N87 & 11 & $2 \times 11$ & 1.59 & 1.45 & 95.4 & $\mathbf{3 . 1 4 e - 2}$ & 150 \\
\hline & C058716 HF60 & 10 & 36 & 2.68 & 5.41 & 100.9 & $2.96 \mathrm{e}-2$ & 150 \\
& 77109A7 KM125 & 10 & 40 & 2.20 & 6.40 & 95.1 & $3.72 \mathrm{e}-2$ & 150 \\
(c) 70 & C055087 MPP160 & 10 & 30 & 3.20 & 4.59 & 103.2 & $\mathbf{2 . 7 2 e - 2}$ & 150 \\
\hline
\end{tabular}

In order to better compare the compromise between switching frequency and volume, one must also consider the heatsinks volume used in the design. The filter capacitors volume is neglected, since the first stage capacitor of the filter has the same capacitance for the two considered switching frequencies and do not change the volume ratio of the projects (Table I). Heatsinks available from Fischer Elektronik are considered. The smallest heatsink volume that can allocate 6 switches and 7 diodes with TO-247 packages and respect the maximum temperature rise at the junction is the Fischer LAM 3150 heatsink. Table IV shows the total volume of the magnetic components and heatsinks considering the quantity of each item. The selection of the switching frequency of $150 \mathrm{kHz}$ is justified because a design with smaller volume is achieved.

Although the optimization routine was used on more than 766 Magnetics toroidal cores and 46 Epcos type E cores, the final choice depended on the laboratory availability. In practice the cores available for the construction of the converter were the toroidal iron powder 0078439A7 material XF-60 from Magnetics for the input filter, the ferrite core E55/28/25 with material N87 from Epcos for the interphase transformer and the toroidal iron powder

\section{TABLE IV}

Comparison of the total volume and power density considering the magnetic components, capacitors and heatsinks for two switching frequencies.

\begin{tabular}{cccc}
\hline Component & Quantity & $f_{\mathrm{sw}}=45 \mathrm{kHz}$ & $f_{\mathrm{sw}}=150 \mathrm{kHz}$ \\
\hline Heatsinks & 2 & $2.70 \mathrm{e}-1 \mathrm{dm}^{3}$ & $2.70 \mathrm{e}-1 \mathrm{dm}^{3}$ \\
Input filter inductors & 3 & $1.41 \mathrm{e}-1 \mathrm{dm}^{3}$ & $8.64 \mathrm{e}-2 \mathrm{dm}^{3}$ \\
Interphase transformers & 2 & $1.15 \mathrm{e}-1 \mathrm{dm}^{3}$ & $6.28 \mathrm{e}-2 \mathrm{dm}^{3}$ \\
Output inductor & 1 & $6.55 \mathrm{e}-2 \mathrm{dm}^{3}$ & $2.72 \mathrm{e}-2 \mathrm{dm}^{3}$ \\
Input filter capacitors & 12 & $1.58 \mathrm{e}-1 \mathrm{dm}^{3}$ & $1.58 \mathrm{e}-1 \mathrm{dm}^{3}$ \\
Output capacitor & 1 & $1.01 \mathrm{e}-1 \mathrm{dm}^{3}$ & $1.01 \mathrm{e}-1 \mathrm{dm}^{3}$ \\
\hline Total Volume & - & $8.49 \mathrm{e}-1 \mathrm{dm}^{3}$ & $7.05 \mathrm{e}-1 \mathrm{dm}^{3}$ \\
Power Density & - & $7.06 \mathrm{~kW} / \mathrm{dm}^{3}$ & $8.51 \mathrm{~kW} / \mathrm{dm}^{3}$ \\
\hline Magnetics Volume & - & $3.21 \mathrm{e}-1 \mathrm{dm}^{3}$ & $1.76 \mathrm{e}-1 \mathrm{dm}^{3}$ \\
Power Density & - & $18.69 \mathrm{~kW} / \mathrm{dm}^{3}$ & $34.02 \mathrm{~kW} / \mathrm{dm}^{3}$ \\
\hline
\end{tabular}

TABLE V

Optimization results considering the two different operating points, switching frequency of $150 \mathrm{kHz}$ and ambient temperature of $40^{\circ} \mathrm{C}$ : (a) Input filter; (b) Interphase transformer; (c) Output inductor.

\begin{tabular}{|c|c|c|c|c|c|c|c|}
\hline \multicolumn{8}{|c|}{ Worst operating point for each case } \\
\hline $\begin{array}{l}L_{\mathrm{p}, \min } \\
{[\mu \mathrm{H}]}\end{array}$ & Core & AWG & $N$ & $\begin{array}{c}P_{\mathrm{C}} \\
{[\mathrm{W}]}\end{array}$ & $\begin{array}{c}P_{\mathrm{W}} \\
{[\mathrm{W}]}\end{array}$ & $\begin{array}{c}T_{\mathrm{f}} \\
{\left[{ }^{\circ} \mathrm{C}\right]}\end{array}$ & $\begin{array}{c}\text { Vol } \\
{\left[\mathrm{dm}^{3}\right]}\end{array}$ \\
\hline (a) 286.6 & 0078439A7 XF60 & 18 & 58 & $1.51 \mathrm{e}-2$ & 4.56 & 95.8 & $3.35 \mathrm{e}-2$ \\
\hline (b) 470 & E55/28/25 N87 & 15 & $2 \times 9$ & 1.50 & 0.88 & 72.9 & $6.69 \mathrm{e}-2$ \\
\hline (c) 70 & C055195A2 MPP125 & 18 & 20 & 3.31 & 4.39 & 93.4 & $3.53 \mathrm{e}-2$ \\
\hline \multicolumn{8}{|c|}{ Nominal operating point $M=0.816$} \\
\hline $\begin{array}{l}L_{\mathrm{p}, \min } \\
{[\mu \mathrm{H}]}\end{array}$ & Core & AWG & $N$ & $\begin{array}{c}P_{\mathrm{C}} \\
{[\mathrm{W}]}\end{array}$ & $\begin{array}{c}P_{\mathrm{W}} \\
{[\mathrm{W}]}\end{array}$ & $\begin{array}{c}T_{\mathrm{f}} \\
{\left[{ }^{\circ} \mathrm{C}\right]}\end{array}$ & $\begin{array}{c}\text { Vol } \\
{\left[\mathrm{dm}^{3}\right]}\end{array}$ \\
\hline (a) 286.6 & 0078439A7 XF60 & 18 & 58 & $1.46 \mathrm{e}-2$ & 4.36 & 93.7 & $3.35 \mathrm{e}-2$ \\
\hline (b) 470 & E55/28/25 N87 & 15 & $2 \times 9$ & 0.77 & 0.78 & 61.7 & $6.69 \mathrm{e}-2$ \\
\hline (c) 70 & C055195A2 MPP125 & 18 & 20 & 2.25 & 4.29 & 86.3 & $3.53 \mathrm{e}-2$ \\
\hline & Magnetics Volume & & & \multicolumn{4}{|c|}{$2.70 \mathrm{e}-1 \mathrm{dm}^{3}$} \\
\hline & Power Density & & & \multicolumn{4}{|c|}{$22.26 \mathrm{~kW} / \mathrm{dm}^{3}$} \\
\hline
\end{tabular}

from Magnetics C055195A2 material MPP125 for the output filter. Considering an ambient temperature of $40^{\circ} \mathrm{C}$ and the switching frequency at $150 \mathrm{kHz}$, the number of turns for each magnetic is calculated according to the minimum inductance specifications. The losses and the final temperature are given in Table $\mathrm{V}$ for the worst case and for nominal operation. The magnetic components have higher volume when compared to the results shown in Table III for the $150 \mathrm{kHz}$ switching frequency.

A 6-kW prototype with the optimized magnetics was constructed as seen in Figure 19 with the specifications given in Table VI.

TABLE VI

5L-CSR Specification.

\begin{tabular}{lc}
\hline RMS phase Voltage $U_{\mathrm{g}}^{\text {rms }}$ & $220 \mathrm{~V}$ \\
dc output voltage $U_{\mathrm{dc}}$ & $380 \mathrm{~V}$ \\
Mains frequency $f_{\mathrm{g}}$ & $60 \mathrm{~Hz}$ \\
Switching frequency $f_{\mathrm{sw}}$ & $150 \mathrm{kHz}$ \\
Output power $P_{\text {out }}$ & $6.0 \mathrm{~kW}$ \\
Dc capacitor $C_{\mathrm{dc}}$ & $50 \mu \mathrm{F}$ \\
Filter capacitor $C_{\mathrm{F}}$ & $4.7 \mu \mathrm{F}$ \\
Filter inductor $L_{\mathrm{F}}$ & $287 \mu \mathrm{H}$ \\
Dc inductor $L_{\mathrm{dc}}$ & $70 \mu \mathrm{H}$ \\
IPT magnetizing inductance $L_{\mathrm{mag}}$ & $470 \mu \mathrm{H}$ \\
\hline
\end{tabular}

The converter power density may be defined as the relation of the maximum output power and the total volume of the converter, when considering the converter a boxed volume, as shown in Figure 19, a $1.1 \mathrm{~kW} / \mathrm{dm}^{3}$ power density is achieved. However, this study aims to optimize the magnetic components, only this volume must be considered in comparison to previous work: a $7.5 \mathrm{~kW} / 28 \mathrm{kHz} 3 \mathrm{~L}-\mathrm{CSR}$ 


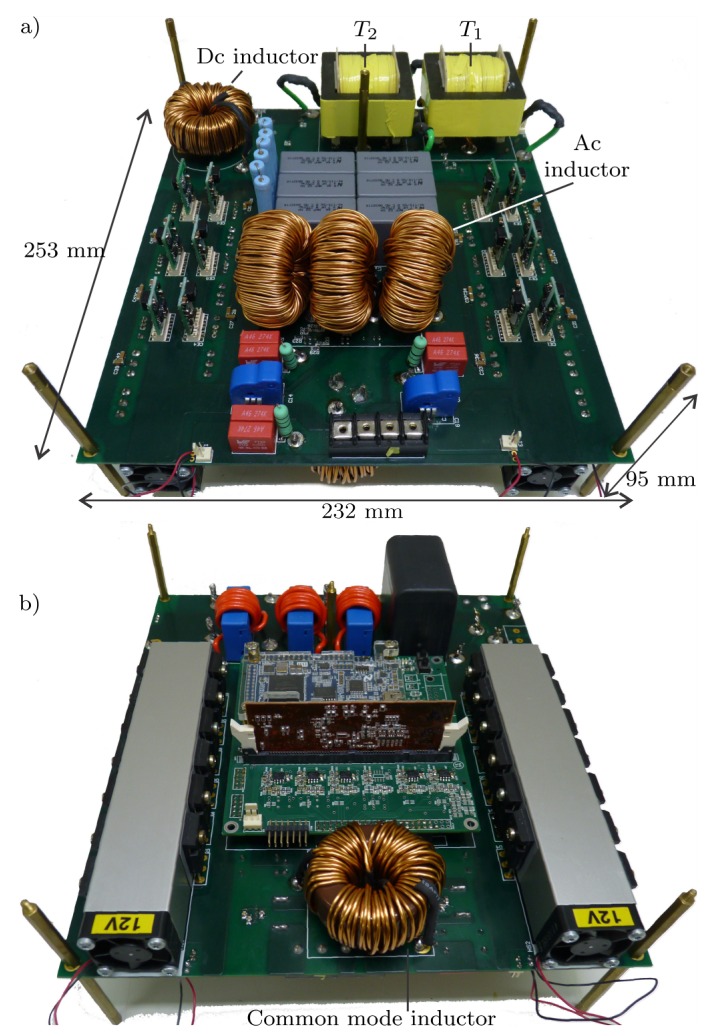

Fig. 19. 6-kW 5-level CSR prototype: (a) top side view; and, (b) bottom view.

with $11.51 \mathrm{~kW} / \mathrm{dm}^{3}$ power density, considering the volume distribution of $12 \%$ to magnetics input filter and $34 \%$ to output inductor [30]. The 5L-CSR achieved a $22.26 \mathrm{~kW} / \mathrm{dm}^{3}$ power density when considering only the magnetics volume. It is important to note that the size of the magnetic components final choice depended on the laboratory availability and if the construction of the converter were made with the magnetics components given in Table IV, the power density would grow to $34.02 \mathrm{~kW} / \mathrm{dm}^{3}$.

The 6-kW 5L-CSR prototype was tested at the rated operating point. Figure 20 presents the time behavior of the output voltage $u_{\mathrm{dc}}$, output current $i_{\mathrm{dc}}$, input voltage $u_{\mathrm{a}}$ and input current $i_{\mathrm{a}}$. Figure 21 shows the time behavior of the interphase transformer currents $i_{\mathrm{p}, 1}$ and $i_{\mathrm{p}, 2}$, input voltage $u_{\mathrm{a}}$ and voltages across the transformer windings $u_{\mathrm{pp}}$. Current $i_{\mathrm{a}}$ follows the sinusoidal input phase voltage $u_{\mathrm{a}}$ and thus, a near unity power factor is achieved. The currents of the interphase transformed are balanced although it presents a small steady state error $\left(i_{\mathrm{T}}=160 \mathrm{~mA}\right)$. The output voltage is regulated at $u_{\mathrm{dc}}=380 \mathrm{~V}$ and the output current is $i_{\mathrm{dc}}=15.79 \mathrm{~A}$.

Temperatures were measured using a FLIR A655sc Infrared Camera as seen in Figure 22. The final temperatures at the magnetic components were closely matched with the ones given in Table V for nominal operation. Predicted temperature rise errors were lower than $15,0 \%$.

\section{CONCLUSIONS}

An optimization procedure for the design of the magnetic components for a 5-level CSR was presented based on practical design requirements and aiming at the minimization of the overall converter volume. To the knowledge of the

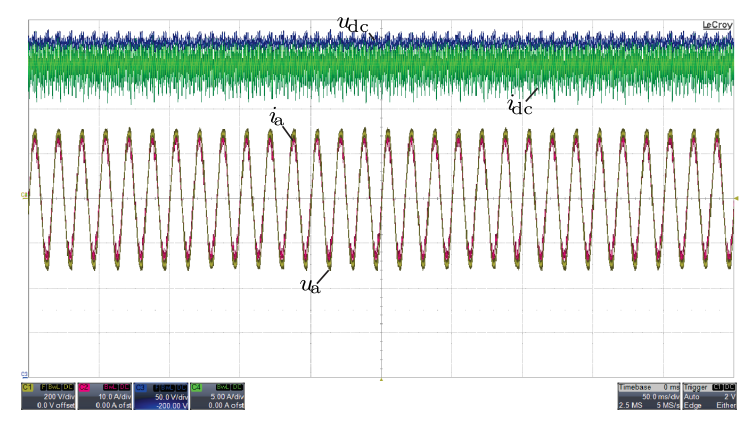

Fig. 20. Experimental results of the 6-kW 5-level CSR prototype: $u_{\mathrm{dc}}$ $(50.0 \mathrm{~V} / \mathrm{div}$ and $-200.0 \mathrm{~V}$ offset $), i_{\mathrm{dc}}(5.0 \mathrm{~A} / \mathrm{div}), u_{\mathrm{a}}(50.0 \mathrm{~V} / \mathrm{div})$ and $i_{\mathrm{a}}(10.0 \mathrm{~A} / \mathrm{div})$.

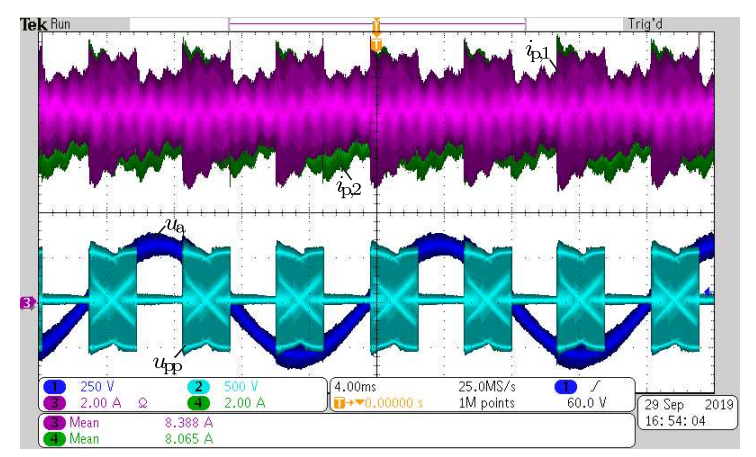

Fig. 21. Waveforms of the 6-kW 5-level CSR prototype: $i_{\mathrm{p}, 1}(2.0$ $\mathrm{A} /$ div and $-4.0 \mathrm{~A}$ offset $), i_{\mathrm{p}, 2}(2.0 \mathrm{~A} / \mathrm{div}$ and $-4.0 \mathrm{~A}$ offset $), u_{\mathrm{dc}}(200.0$ $\mathrm{V} /$ div and $-400.0 \mathrm{~V}$ offset $)$ and $u_{\mathrm{a}}(200.0 \mathrm{~V} /$ div and $-400.0 \mathrm{~V}$ offset $)$.

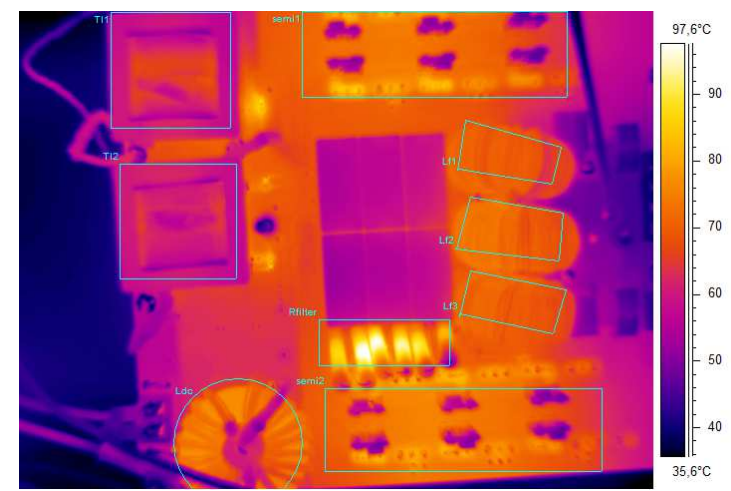

Fig. 22. Temperature measurement using a FLIR A655sc Infrared Camera. Ambient temperature was $40^{\circ} \mathrm{C}$. Maximum temperatures: input inductors was $80.2^{\circ} \mathrm{C}$; interphase transformers was $67.5^{\circ} \mathrm{C}$; output inductor was $93.7^{\circ} \mathrm{C}$.

authors the proposed procedure is critical in real applications for this type of converter and has not been previously performed. CSRs are typically seen as having worst performance than voltage source converters and the optimum design of their components is critical if this is to change for any given application.

The input filter inductors, interphase transformers and output inductor were considered and a design based on a system perspective was proposed. The optimization methodology was exemplarily performed for two switching frequencies, namely $45 \mathrm{kHz}$ and $150 \mathrm{kHz}$.

The magnetic optimization is initialized with the specification of the inductance values, which is based on the worst operating case, EMC, losses and thermal 
constraints. The required geometric and magnetic parameters were defined, where it was shown that the Steinmetz coefficients are advantageously updated for the different values of induction and frequency since these change at each switching period of the 5-level CSR. The Steinmetz coefficients dependence on temperature is negligible for the design cases with iron powder cores because the optimal design tends to lead to a temperature close to the defined maximum. However, the behavior was quite different for the ferrite cores used in the interphase transformer and the coefficients were updated accordingly. Dowell's equation was used to compute the copper losses since no air gap is used in the considered components. The iGSE method was used to calculate the core losses with the Steinmetz coefficients updated for each switching period.

The optimization results show that a $150 \mathrm{kHz}$ switching frequency is justified since it results in a reasonably smaller overall converter volume. The experimental prototype reached an efficiency at $6.0 \mathrm{~kW}$ of $97.0 \%$ and a power density of approximately $22.26 \mathrm{~kW} / \mathrm{dm}^{3}$ when considering only the magnetics volume. A $1.1 \mathrm{~kW} / \mathrm{dm}^{3}$ overal power density, considering the converter boxed volume, was achieved. Such values are close to the ones reported for voltage source rectifiers employing conventional components and cooling methods.

\section{REFERENCES}

[1] L. K. Ries, M. L. Heldwein, "Current Balancing Control Methods using Advanced Carrier-Based Modulation for Five-Level Current Source Rectifiers", IEEE Transactions on Power Electronics, pp. 1-1, 2020, doi:10.1109/TPEL.2020.2982051.

[2] M. Yanagihara, K. Nakazawa, T. Morita, Y. Uemoto, "Bidirectional switch", US Patent 8,344,463, issued January 1, 2013.

[3] H. Umeda, Y. Yamada, K. Asanuma, F. Kusama, Y. Kinoshita, H. Ueno, H. Ishida, T. Hatsuda, T. Ueda, "High power 3-phase to 3-phase matrix converter using dual-gate GaN bidirectional switches", in IEEE Applied Power Electronics Conference and Exposition (APEC), pp. 894-897, 2018, doi: 10.1109/APEC.2018.8341119.

[4] M. Baumann, U. Drofenik, J. W. Kolar, "New wide input voltage range three-phase unity power factor rectifier formed by integration of a three-switch buck-derived front-end and a DC/DC boost converter output stage", Twentysecond International Telecommunications Energy Conference (INTELEC), pp. 461-470, 2000, doi: 10.1109/INTLEC.2000.884290.

[5] M. Baumann, J. W. Kolar, "Parallel Connection of Two Three-Phase Three-Switch Buck-Type UnityPower-Factor Rectifier Systems With DC-Link Current Balancing", IEEE Transactions on Industrial Electronics, vol. 54, no. 6, pp. 3042-3053, 2007, doi:10.1109/TIE.2007.907006.

[6] N. Binesh, B. Wu, "5-level parallel current source inverter for high power application with DC current balance control", in IEEE International Electric
Machines \& Drives Conference (IEMDC), pp. 504509, 2011, doi:10.1109/IEMDC.2011.5994649.

[7] D. $\mathrm{Xu}, \mathrm{B} . \mathrm{Wu}$, "Space vector modulation for high power five level current source inverters", in 37th IEEE Power Electronics Specialists Conference, pp. 1-6, 2006, doi:10.1109/pesc.2006.1711812.

[8] Y. Xiangwu, Z. Bo, G. Xiaobin, Z. Lixia, L. Heming, "Double Closed-loop Control of Three-Phase Fivelevel PWM Current Source Inverter", in IECON 2007 - 33rd Annual Conference of the IEEE Industrial Electronics Society, pp. 2110-2114, 2007, doi: 10.1109/IECON.2007.4460360.

[9] M. Baumann, J. W. Kolar, "Experimental evaluation of space vector oriented active DC-side current balancing of two parallel connected three-phase threeswitch buck-type unity power factor rectifier systems", 24th Annual International Telecommunications Energy Conference (INTELEC), pp. 317-324, 2002, doi: 10.1109/INTLEC.2002.1048674.

[10] J. Bao, W. Bao, Z. Zhang, W. Fang, "A simple current-balancing method for a three-phase 5-level current-source inverter", in 35th Annual Conference of IEEE Industrial Electronics, pp. 104-108, 2009, doi: 10.1109/IECON.2009.5414790.

[11] B. S. Dupczak, A. J. Perin, M. L. Heldwein, "Space Vector Modulation Strategy Applied to Interphase Transformers-Based Five-Level Current Source Inverters", IEEE Transactions on Power Electronics, vol. 27, no. 6, pp. 2740-2751, 2012, doi: 10.1109/TPEL.2011.2177479.

[12] L. K. Ries, T. B. Soeiro, M. S. Ortmann, M. L. Heldwein, "Analysis of Carrier-Based PWM Patterns for a Three-Phase Five-Level Bidirectional Buck +Boost-Type Rectifier", IEEE Transactions on Power Electronics, vol. 32, no. 8, pp. 6005-6017, 2017, doi: 10.1109/TPEL.2016.2619161.

[13] K. B. Park, F. D. Kieferndorf, U. Drofenik, S. Pettersson, F. Canales, "Weight Minimization of LCL Filters for High-Power Converters: Impact of PWM Method on Power Loss and Power Density", IEEE Transactions on Industry Applications, vol. 53, no. 3, pp. 2282-2296, 2017, doi:10.1109/TIA.2017.2657479.

[14] N. R. Coonrod, "Transformer Computer Design Aid for Higher Frequency Switching Power Supplies", IEEE Transactions on Power Electronics, vol. PE-1, no. 4, pp. 248-256, 1986, doi: 10.1109/TPEL.1986.4766317.

[15] E. L. Barrios, A. Ursúa, L. Marroyo, P. Sanchis, "Analytical Design Methodology for Litz-Wired HighFrequency Power Transformers", IEEE Transactions on Industrial Electronics, vol. 62, no. 4, pp. 2103 2113, 2015, doi:10.1109/TIE.2014.2351786.

[16] M. Leibl, G. Ortiz, J. W. Kolar, "Design and Experimental Analysis of a MediumFrequency Transformer for Solid-State Transformer Applications", IEEE Journal of Emerging and Selected Topics in Power Electronics, vol. 5, no. 1, pp. 110-123, 2017, doi:10.1109/JESTPE.2016.2623679. 
[17] A. Müsing, J. W. Kolar, "Successful online education - GeckoCIRCUITS as open-source simulation platform", in International Power Electronics Conference (IPEC-Hiroshima 2014 - ECCE ASIA), pp. 821-828, 2014, doi:10.1109/IPEC.2014.6869683.

[18] T. Nussbaumer, M. L. Heldwein, J. W. Kolar, "Differential mode EMC input filter design for a threephase buck-type unity power factor PWM rectifier", in IPEMC 2004 - The 4th International Power Electronics and Motion Control Conference, vol. 3, pp. 1521-1526 Vol.3, 2004.

[19] M. L. Heldwein, T. Nussbaumer, J. W. Kolar, "Differential mode EMC input filter design for three-phase AC-DC-AC sparse matrix PWM converters", in IEEE 35th Annual Power Electronics Specialists Conference (IEEE Cat. No.04CH37551), vol. 1, pp. 284-291 Vol.1, 2004, doi:10.1109/PESC.2004.1355757.

[20] D. O. Boillat, J. W. Kolar, "Modeling and experimental analysis of a Coupling Inductor employed in a high performance AC power source", International Conference on Renewable Energy Research and Applications (ICRERA), pp. 1-18, 2012, doi: 10.1109/ICRERA.2012.6477401.

[21] J. Brown, "Modeling the switching performance of a MOSFET in the high side of a non-isolated buck converter", IEEE Transactions on Power Electronics, vol. 21, no. 1, pp. 3-10, 2006, doi: 10.1109/TPEL.2005.861110.

[22] M. J. Jacoboski, Conversor CC-CC Isolado Duplo NPC com Comutação Suave: Estudo, Projeto $e$ Implementação, Thesis, Programa de Pós-Graduação em Engenharia Elétrica, Universidade Federal de Santa Catarina, Florianópolis, SC, 2015.

[23] P. L. Dowell, "Effects of eddy currents in transformer windings", Electrical Engineers, Proceedings of the Institution of, vol. 113, no. 8, pp. 1387-1394, 1966, doi:10.1049/piee.1966.0236.

[24] L. Jieli, T. Abdallah, C. R. Sullivan, "Improved calculation of core loss with nonsinusoidal waveforms", in Conference Record of the 2001 IEEE Industry Applications Conference: Thirty-Sixth IAS Annual Meeting, vol. 4, pp. 2203-2210 vol.4, 2001, doi:10.1109/IAS.2001.955931.

[25] J. Reinert, A. Brockmeyer, R. W. A. A. De Doncker, "Calculation of losses in ferro- and ferrimagnetic materials based on the modified Steinmetz equation", IEEE Transactions on Industry Applications, vol. 37, no. 4, pp. 1055-1061, 2001, doi:10.1109/28.936396.

[26] K. Venkatachalam, C. R. Sullivan, T. Abdallah, H. Tacca, "Accurate prediction of ferrite core loss with nonsinusoidal waveforms using only Steinmetz parameters", in Proceedings of 2002 IEEE Workshop on Computers in Power Electronics, pp. 36-41, 2002, doi:10.1109/CIPE.2002.1196712.

[27] C. W. T. McLyman, Transformer and Inductor Design Handbook, Third Edition, 3rd ed., CRC Press, 2014.

[28] I. Villar, U. Viscarret, I. Etxeberria-Otadui, A. Rufer, "Transient thermal model of a medium frequency power transformer", in 34th Annual Conference of IEEE Industrial Electronics, pp. 1033-1038, 2008, doi:10.1109/IECON.2008.4758096.

[29] S. Purushothaman, F. de Leon, "Heat-Transfer Model for Toroidal Transformers", IEEE Transactions on Power Delivery, vol. 27, no. 2, pp. 813-820, 2012, doi: 10.1109/TPWRD.2012.2185956.

[30] F. Xu, B. Guo, L. M. Tolbert, F. Wang, B. J. Blalock, "Evaluation of SiC MOSFETs for a high efficiency three-phase buck rectifier", in Twenty-Seventh Annual IEEE Applied Power Electronics Conference and Exposition (APEC), pp. 1762-1769, 2012.

\section{BIOGRAPHIES}

Lisandra Kittel Ries received the B.S., M.S and Ph.D. degrees in electrical engineering from the Federal University of Santa Catarina, Florianópolis, Brazil, in 2010 and 2013, respectively. She also received the B.S. and M.S. degrees in electrical engineering from the Institut National Polytechnique of Toulouse, Toulouse, France, in 2010.

She is currently an Adjunct Professor with the Electrotechnical Department, Federal Institute of Education, Science and Technology of Santa Catarina, Florianópolis, Brazil.

Marcelo Lobo Heldwein (S'99-M'08-SM'13) received the B.S. and M.S. degrees in electrical engineering from the Federal University of Santa Catarina (UFSC), Florianópolis, Brazil, in 1997 and 1999, respectively, and his Ph.D. degree from the Swiss Federal Institute of Technology (ETH Zurich), Zurich, Switzerland, in 2007.

He is currently an Associate Professor with the Department of Electronics and Electrical Engineering at the UFSC. From 1999 to 2003, he worked with industry, including R\&D activities at the Power Electronics Institute, Brazil and Emerson Network Power, Brazil and Sweden. He was a Postdoctoral Fellow at the ETH Zurich and at the UFSC from 2007 to 2009. Dr. Heldwein is a member of the Brazilian Power Electronic Society (SOBRAEP). He is also a member of the Advisory Board of PCIM Europe and an Associated Editor of the IET The Journal of Engineering.

His research interests include Power Electronics, Advanced Power Distribution Technologies and Electromagnetic Compatibility. 